\title{
Navigating the wilderness Another view of the information landscape
}

W hen searching for materials on the Web, students do not always make a distinction between resources the library pays for and those that are free. In finding free relevant resources, one view we find in literature is the need to map the Web so we librarians can help students navigate through this "information landscape" that is not under our control. The emphasis in those articles is consistent with my function as a cataloger-that of creating access points and linking those points to the physical or virtual information resources.

The links between access points and resources may be call numbers, government documents numbers, journal citations, or PURLs. However, my noncataloging side would like to present a different view of the same information landscape. This view has mostly remained in the background in my mind over the years. But it has surfaced from time to time, and more recently due to two sources.

The first is the keynote address that Michael Jensen gave at the 2006 conference of the Illinois Association of College and Research Libraries (IACRL), where he spoke about the scholarly ecosystem. In a newsletter article I wrote at the time, I said that two of the pictures he showed in the presentation encapsulate two basic worldviews that we face as librarians. ${ }^{1}$ One is the wilderness and the other is a manicured garden.

The manicured garden is the view that our OPACs and other access tools give where there are clearly delineated gardens of materials in the sciences, the humanities, the social sciences and so forth, with wellestablished paths throughout the garden to reach specific spots. The charted paths allow quick access to each flower bed of related resources. But access to other kinds of groupings and relationships, including uncataloged items, may be impeded.

However, with the speed that new information becomes available, the wilderness is really closer to the view of the information landscape that we have to deal with, particularly with abundant Web resources that appear or are updated by the minute.

The second is an article entitled "Leadership as the Legitimation of Doubt" by Karl Weick. ${ }^{2}$ He said that to lead in the 21 st century is less about decision-making and more about sensemaking. It is a world that one gets thrown in where one must deal with "shifting patterns of relationships" in environments that may be unknowable and unpredictable. ${ }^{3}$ Given this context, one navigates by using a compass rather than a map because terrains subject to continuous change cannot be easily mapped. In such a partly charted world with shifting landmarks, one must improvise to create plausible and feasible solutions. Thus saying "I don't know" becomes a prelude to sensemaking. Applying this idea of using a

Felix Chu is assessment/cataloging librarian at Western Illinois University's Malpass Library, e-mail: F-Chu@ wiu.edu

(c) 2011 Felix Chu 
compass instead of a map, navigating the information landscape becomes a process of sensemaking.

Whether we think of the information landscape as a physical or a virtual space, a map is useful only if we try to cross a region that has been charted by someone and remains relatively permanent in patterns of organization.

For example, if a student is looking for materials on the history of 19th-century Illinois or biographical information on Barbara Kingsolver, the process is relatively easy because those topics parallel information organization in libraries. However, if a student wants materials about cultural forces in the interplay between fundamental Christians and fundamental Muslims in social networks, much of relevant information will be on the Web where it sometimes unknowable and often unpredictable. In such a wilderness, there is no detailed map to guide our every step. In helping our students, we have to use a compass, guided by the lay of the land which forms the context.

In the present environment of continuous change, many times with local constraints or needs, it becomes relatively hard to even follow a path that another library or person has charted because that path may no longer exist after the most recent storm.

So we need to proceed by our knowledge of general landscape features and patterns of information organization. This knowledge may be tacit that we acquire through experience. Sometimes we go in an apparently straight line only to find that we are on a cliff. But it is only from that vantage point we get an overview of how to cross a river or a ravine. Then our back-tracking becomes purposeful. We are not wandering in the wilderness. Instead we become improvisational in establishing a strategy to cross the next obstacle. Sometimes it is easier to just sit and wait out the next storm before continuing. This is where we have to use a compass, our knowledge base, and our experiences to improvise a strategy for moving forward in the information landscape. Even if a path has been charted, it is only good before the next growing season, the next storm, or even the next day.

In the manicured garden, we use maps. Our aim is to find the most effective and efficient path to reach a known objective. In the wilderness, we must use a compass to set directions, rely on our understanding of information organization and patterns to craft possible paths, and use our knowledge to recognize when we have found what we are seeking. This is when we look for efficacious search strategies and satisficing solutions. We show the students a direction and give them rules of thumb established through our experience so that they may have a very good chance of finding what they need.

\section{Notes}

1. "Musings on the 2006 IACRL Conference," IACRL Newsletter 29 (Fall 2006): 1, 10, 12. Available online at http://iacrl.net /Newsletters/2006fall.pdf.

2. The Future of Leadership: Today's Top Leadership Thinkers Speak to Tomorrow's Leaders, eds. Warren Bennis, Gretchen M. Spreitzer, and Thomas G. Cummings (San Francisco: Jossey-Bass, 2001), 91-102.

3. Ibid., 92. $n$

("I came, I saw, I researched," cont. from page 340)

3. Larry Smith and Rachel Fershleiser, $I$ Can't Keep My Own Secrets: Six-Word Memoirs by Teens Famous \& Obscure (New York: HarperTeen, 2009).

4. Nancy Stetson, "Six Words, One Idea, Intriguing Challenge: Mini-Memoirs Summarize a Life," Fort Myers Florida Weekly, June 18, 2008, accessed March 12, 2011, http:// fortmyers.floridaweekly.com/news/2008-0618/arts_ent/061.html.

5. John, Yohe, "Using Six-Word Memoirs as an Icebreaker and Introduction to the Writing Process," Teaching English in the Two Year College 38, no. 1 (September 2010): 80-81. n 